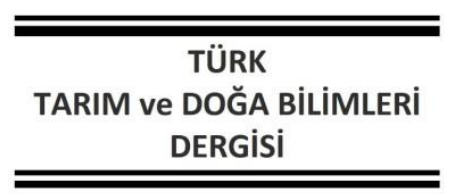

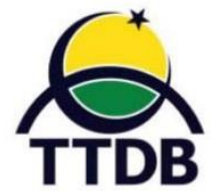

www.dergipark.gov.tr/turkjans

Araştırma Makalesi

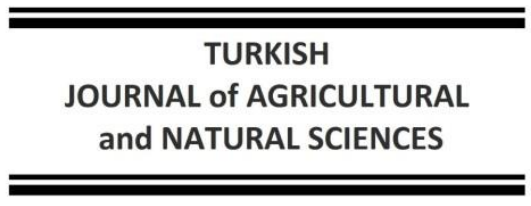

OURNAL Of AGRICULTURAL and NATURAL SCIENCES

\title{
Artırılmış Karbondioksit ve Sıcaklığın Reyhan Bitkisinin Gelişimi Üzerine Etkileri
}

\author{
Ayşe Özlem TURSUN ${ }^{1}$, Veli UYGUR², ìsa TELCi³ \\ ${ }^{1}$ Malatya Turgut Özal Üniversitesi Battalgazi MYO, Malatya \\ ${ }^{2}$ Isparta Uygulamalı Bilimler Üniversitesi Ziraat Fakültesi, Toprak Bilimi ve Bitli Besleme Böl. Isparta \\ ${ }^{3}$ Isparta Uygulamalı Bilimler Üniversitesi Ziraat Fakültesi, Tarla Bitkileri Bölümü Isparta \\ *Sorumlu Yazar: ozlem.tursun@ozal.edu.tr
}

Geliş Tarihi: 20.02.2021 Düzeltme Geliş Tarihi: 11.06.2021 Kabul Tarihi: 29.06.2021

\section{Öz}

Artan sıcaklık ve karbondioksit konsantrasyonu küresel çevrenin değişimine neden olmaktadır. Küresel çevredeki meydana gelen bu değişimin tarımsal üretim açısından nasıl sonuçlanacağı önemlidir. Lamiaceae familyasından değerli bir uçucu yağ ve baharat bitkisi olan reyhanın (Ocimum basilicum L.) arttırılmış sıcaklık ve karbondioksit konsantrasyonlarında bitki gelişimi ve besin elementleri kompozisyonunu belirlemek amacıyla bu çalışma Malatya Turgut Özal Üniversitesi Ziraat Fakültesi'ne ait olan tam otomasyonlu karbondioksit serasında yapılmıştır. Araştırmada 3 farklı sıcaklık $\left(26 / 16,29 / 19\right.$ ve $\left.32 / 22{ }^{\circ} \mathrm{C}\right)$ ve 4 farklı $\mathrm{CO}_{2}$ konsantrasyonları $(400 \pm 50$, $600 \pm 50,800 \pm 50$ ve $1000 \pm 50$ ppm) kullanılmıştır. Çalışma sonucunda çimlenme oranı $\left(G_{\max }\right)$, taze ve kuru herba verimi, bitki boyu ve kuru madde içeriği sıcaklık artışından etkilenirken, bitki boyu ise karbondioksit artışından etkilenmiştir. Reyhan bitkisinin besin elementleri komposizyonunda ise; $\mathrm{CO}_{2}$ artışı $\mathrm{P}, \mathrm{K}, \mathrm{Cu}, \mathrm{Ca}$ ve Fe'de azalışlar meydana getirirken, diğer elementlerde dalgalanmalar belirlenmiş, sıcaklık ise reyhan bitkisinin topraktan kaldırdığı besin elementi miktarında özellikle de makro elementler üzerine etkisi son derece belirgin olmuştur.

Anahtar kelimeler: Artırılmış karbondioksit ve sıcaklık, reyhan, besin elementi

\section{The Effects of Increased Carbon Dioxide and Temperature on the Development of the Basil Plant}

\begin{abstract}
Increasing temperature and carbon dioxide concentration cause changes in the global environment. It is important how this change in the global environment will result in terms of agricultural production. This study was carried out in a fully automated carbon dioxide greenhouse belonging to Malatya Turgut Özal University Faculty of Agriculture in order to determine the plant growth and nutrient composition of basil (Ocimum basilicum L.), a valuable essential oil and spice plant from the Lamiaceae family, at elevated temperature and carbon dioxide concentrations.In this study; 3 different temperatures (26/16, 29/19 and $32 / 22{ }^{\circ} \mathrm{C}$ ) and 4 different $\mathrm{CO}_{2}$ concentrations $(400 \pm 50,600 \pm 50,800 \pm 50$ and $1000 \pm 50 \mathrm{ppm}$ ) were used. As a result of the study, the germination rate $\left(G_{\max }\right)$, fresh and dry herb yield, plant height and dry matter content were affected by increase temperature, while the plant height was affected by the increase in elevated carbon dioxide. In the nutritional composition of the basil plant; while the increase in $\mathrm{CO}_{2}$ caused a decrease in $\mathrm{P}, \mathrm{K}$, $\mathrm{Cu}, \mathrm{Ca}$ and $\mathrm{Fe}$, fluctuations were determined in other elements, and the temperature had a very significant effect on the amount of nutrients removed by the basil plant from the soil, especially on the macro elements.
\end{abstract}

Key words: Elevated carbon dioxide and increased temperature, basil, nutrient element

\section{Giriş}

Günümüz dünyasının en önemli sorunlardan biri bütün canlıları etkileyen küresel ısınma ve bunun sonucu ortaya çıkan iklim değişiklikleridir. Sanayi devrimiyle birlikte fosil yakıtlarının (petrol, kömür, doğal gaz vb.) tüketimi 
atmosferde karbondioksit, metan $\left(\mathrm{CH}_{4}\right)$, diazot monoksit $\left(\mathrm{N}_{2} \mathrm{O}\right)$ gibi sera gazlarının yoğunluğuna (Böttcher, 1993; Kadıoğlu, 2008) ve bunun sonucunda atmosfer sıcaklığının artışına neden olmuştur (Mall ve ark., 2006). Sanayi devriminin başlangıcından günümüze kadar atmosferdeki karbondioksit miktarı 280 ppm'den 370 ppm'e kadar yükselmiştir. Son yıllarda yapılan araştırmalarda atmosferdeki karbondioksit miktarının yılda 1,8 ppm artığı (Mendelsohn ve Rosenberg, 1994; Etheridge ve ark., 1996; Keeling ve Whorf, 2000) ve bu yüzyılın sonunda 600-1000 ppm'e kadar yükseleceği tahmin edilmektedir (IPCC, 2014; Cox ve ark., 2000). Karbondioksit seviyesinin artması sonucunda küresel boyutta maksimum, minimum ve ortalama sıcaklıkların 3-4 derece artacağı öngörülmektedir (Taylor ve MacCracken, 1990; IPCC, 2014). Karbondioksit seviyesinin artması ve küresel ısınma bitkilerin büyüme/gelişmesine ve bitkisel üretime önemli etkilerinin olacağı kaçınılmazdır (Cox ve ark., 2000; Hansen ve ark., 2000). Yapılan çalışmalarda mısır, pamuk, soya, buğday, çeltik gibi kültür bitkilerinin artan $\mathrm{CO}_{2}$ oranlarına olumlu tepkiler verdiği tespit edilmiştir (Ziska, 2000; Ziska ve Goins, 2006; Patel ve ark., 2008; Zhu ve ark., 2008; Erbs ve ark., 2009). Fakat bu sonuç tüm bitkiler için söz konusu olmayıp sıcaklığa göre karbondioksit etkinliği bitki türlerine göre değişebilmektedir. Sionit ve ark., (1987a) sıcaklık rejimleri arasında karbondioksit zenginleşmesinde toplam soya yaprak alanının arttığını, yaprak kütle oranının karbondioksit uygulamalarında sabit kaldığını, fakat yaprak kütlesinin sıcaklık ve karbondioksit rejimleri ile değiştiğini bildirmişlerdir. Diğer bir ifadeyle bitki büyümesi ve gelişmesi üzerinde artan sıcaklık ve karbondioksit konsantrasyonlarının etkileşimleri (interaksiyonları) ile ilgili araştırmalarda; karbondioksit etkilerinin genellikle artan sıcaklıkla yükseldiği belirlenmiştir (Baker ve ark., 1989, Newman ve ark., 2001). Çalışmalardan bu durumun tüm bitkiler için aynı olmadığı anlaşılmaktadır. Sionit ve ark., (1987b) soya fasulyesinde karbondioksit seviyesindeki bir artışın düşük sıcaklıklarda daha iyi büyümesine neden olduğunu bildirirken, Patel ve Franklin (2009) de sıcaklığın bitki büyümesini ve gelişimini kontrol eden kritik bir faktör olduğunu belirtmektedirler.

Türkiye Tıbbi ve Aromatik bitkileri üretimi ve çeşitliliği bakımından dünyanın önde gelen ülkelerinden birisidir. Lamiaceae familyasından değerli bir uçucu yağ ve baharat bitkisi olan reyhan (Ocimum basilicum L.) Türkiye florasında doğal olarak bulunmamakta ve sadece kültür formlarının yetiştiriciliği yapılmaktadır (Telci ve ark., 2005). Reyhan yaprakları ve çiçeklerinden elde edilen uçucu yağ; gıda aroması, ağız ve diş sağlığı ürünlerinde, parfümeride, kozmetikte, aromaterapide ve geleneksel tıpta yaygın şekilde kullanılmaktadır (Simon ve ark., 1990, Telci ve ark., 2006, Tursun ve Telci, 2020). Ayrıca reyhan uçucu yağının, antioksidan (Bassiouny ve ark., 1990), insektisit (Deshpande ve Tipnis, 1997), antimikrobiyal, fungusit ve herbisit etkileri bulunmaktadır. Mor renkli çeşitleri gıda sanayisi için önemli bir antosiyan kaynağıdır (Simon ve ark., 1999).

Bütün bu açıklamalar ışığında küresel ısınmanın tarımsal üretim açısından hangi sonuçları doğuracağı önemli olmaktadır. Bu nedenlerle, taze ve kuru yaprakları değişik amaçla kullanılan mor renkli reyhanda arttırılmış sıcaklık ve karbondioksit konsantrasyonlarının reyhan bitkisinin çimlenmesi, gelişimi ve besin elementleri kompozisyonu üzerine etkilerini incelemek amacıyla bu çalışma yapılmıştır.

\section{Materyal ve Metot}

Araştırmada bitki materyali olarak, Malatya Arapgir ilçesinde üretimi yapılan yerel reyhan (landraces) kullanılmıştır. $O$. basilicum türüne ait olan bu reyhan "mor renkli" reyhanlar grubunda yer almaktadır (Telci, 2017), Arapgir reyhanı olarak da bilinen bu reyhan bölgede uzun yıllardan beri üretimi yapılmaktadır.

Çalışmalar Malatya Turgut Özal Üniversitesi Ziraat Fakültesi Araştırma Uygulama alanlarında bulunan her biri 25'er m²'lik 4 odalı $\mathrm{CO}_{2}$ takviyeli tam otomasyonlu serada 2019 yılı MartEylül ayları arasında yürütülmüştür. Çalışmada 3 sıcaklık $\left(26 / 16,29 / 19\right.$ ve $\left.32 / 22{ }^{\circ} \mathrm{C}\right)$ ve 4 farklı $\mathrm{CO}_{2}$ konsantrasyonları $(400 \pm 50,600 \pm 50,800 \pm 50$ ve $1000 \pm 50 \mathrm{ppm}$ ) araştırılmıştır. Çalışma Tesadüf parsellerinde faktöriyel deneme desenine göre 4 tekerrürlü olarak kurulmuştur. Odalardaki ışıklandırma 14 saat gündüz, 10 saat gece olacak şekilde ayarlanmıştır. Seranın bulunduğu dış ortamdaki $\mathrm{CO}_{2}$ değeri 370-430 ppm arasında ve IPCC (2007)'ye göre bugün Dünyadaki ortalama sıcaklık ve $\mathrm{CO}_{2}$ değerlerinin $26 / 16{ }^{\circ} \mathrm{C}$ ve $400 \mathrm{ppm}$ olduğu için bu değerler kontrol olarak alınmış ve bu ortamda da bitkiler yetiştirilmiştir. Daha önce yapılan çalışmalar doğrultusunda sıcaklık ve karbondioksitin önümüzdeki senelerde küresel ısınmaya bağlı olarak artacağı tahmin edilmektedir (Franz, 1990, Jenkinson ve ark., 1991, Davidson ve Janssens, 2006). Bu çalışmalar doğrultusunda seradaki sıcaklık ve karbondioksit değerleri artırılmıştır. Serada nem deneme boyunca yaklaşık olarak $\% 60 \pm 10$ olarak ayarlanmıştır.

Denemede 10'ar adet reyhan tohumları eşit oranda toprak/kum/torf/perlit karışımı (1:1:1:1 ağırlık esasına göre) içeren saksılara $(28 \times 22.5 \mathrm{~cm})$ ekilmiştir. Bitkilerin çıkış süreleri takip edilerek 
çimlenme verileri elde edilmiş ve 21 gün sonra her saksıda 1'er adet bitki kalacak şekilde seyreltmeler yapılmıştır.

\section{Çimlenme çalışmaları}

Maksimum çimlenme oranları ( $\left.G_{\max }\right)$ aşağıdaki formüle göre hesaplanmıştır (Akıncı ve Akıncı, 2010).

\section{$(\mathrm{G} / \mathrm{T}) * 100$}

$$
\text { Maksimum Çimlenme Oranı: } \mathrm{G}_{\max }=
$$

Yukarıdaki formüllerde, G: Çimlenen tohum sayısı, $\mathrm{T}$ : denemede kullanılan toplam tohum sayısı etmektedir.

\section{Bitkisel Gelişmeler}

Saksıdaki bitkiler çiçeklenme dönemi başlangıcında boyları (cm) ölçülerek toprak yüzeyinden biçilmiştir. Biçilen taze bitkiler tartılarak taze herba verimi (g/bitki) ve oda şartlarında kurutularak tartılan bitkilerden de kuru herba verimleri ( $\mathrm{g} / \mathrm{bitki}$ ) belirlenmiştir.

\section{Element analizleri}

Çalışmada reyhan bitkisinin daha çok yaprakları tüketildiğinden yapraklarda makro ve mikro besin element kompozisyonu belirlenmiştir. Bunun için; kuru bitki örneklerinden yapraklar mekanik olarak ayrılıp homojen örnek elde edebilmek için çelik bitki öğütme değirmeni ile tanecik boyutu 0,5 mm'nin altında olacak şekilde öğütülmüştür (Kacar ve Inal, 2008). Daha sonra yaş yakma metoduyla örneklerin hot pleyt cihazında yakılmasıyla elde edilen çözeltilerde Kalsiyum (Ca), Magmezyum (Mg), Demir (Fe), Bakır (Cu), Mangan $(\mathrm{Mn})$, Çinko $(\mathrm{Zn})$, Sodyum $(\mathrm{Na})$, Potasyum $(\mathrm{K})$,
Fosfor (P) analizleri ICP-OES ya da AAS cihazında belirlenmiştir.

Bitkilerin azot kapsamları ise Kjeldahl yöntemiyle yakıldıktan sonra alkali ortamda destile edilmiş ve geri titrasyonla titre edilerek toplam azot miktarları aşağıdaki eşitlikle hesaplanmıştır (Kacar ve Inal, 2010).

$$
\mathrm{N}\left(\mathrm{g} \cdot \mathrm{kg}^{-1}\right)=\frac{\left(\mathrm{V}-\mathrm{V}_{0}\right) \times \mathrm{N}_{\mathrm{k}} \times 14}{\mathrm{~T}}
$$

Bu denklemde, Azot ( $\mathrm{N}$ ) bitki materyalinin azot içeriği $\left(\mathrm{g}^{\mathrm{kg}}{ }^{-1}\right), \mathrm{V}$ örnek için harcanan asit çözelti miktarı, $V_{0}$ kör deneme için harcanan asit miktarı, $\mathrm{N}_{\mathrm{k}}$ kullanılan asidin kesin normalitesi, 14 azotun atom ağırlığı $(\mathrm{g} / \mathrm{mol})$ ve $T$ alınan bitki örneğinin ağırlığıdır.

\section{Verilerin değerlendirilmesi}

Bitkisel özeliklerle ilgili verilerin değerlendirilmesinde GLM model One way (ANOVA) varyans analizi uygulanmıştır. Uygulamalar arasındaki fark Duncan çoklu karşılaştırma testi $\quad(\mathrm{P}<0.05) \quad$ kullanılarak bulunmuştur.

\section{Bulgular ve Tartışma}

Çalışmada sıcaklığın etkisi bütün parametrelerde önemli olurken $(p<0.01)$, karbondioksit sadece bitki boyunda önemli $(p<0.05)$ bulunmuş, incelenen diğer özelikleri (anlamlı miktarda) etkilememiştir. İnteraksiyon ise $\mathrm{G}_{\max }(p<0.01)$ önemli bulunmuştur (Çizelge 1$)$.

\begin{tabular}{|c|c|c|c|c|c|c|}
\hline $\begin{array}{l}\text { Sıcaklıklar } \\
\qquad\left({ }^{0} \mathrm{C}\right)\end{array}$ & $\begin{array}{l}\mathrm{CO}_{2} \\
(\mathrm{ppm})\end{array}$ & $\begin{array}{l}G_{\max } \\
(\%)\end{array}$ & $\begin{array}{r}\text { Taze herba } \\
\text { (g/bitki) }\end{array}$ & $\begin{array}{l}\text { Kuru herba } \\
\text { (g/bitki) }\end{array}$ & $\begin{array}{r}\text { Bitki boyu } \\
(\mathrm{cm})\end{array}$ & $\begin{array}{c}\text { Kuru madde } \\
\text { içeriği (\%) }\end{array}$ \\
\hline & 400 & 95.00 & 4.78 & 0.98 & 30.70 & 20.52 \\
\hline \multirow[t]{3}{*}{$26 / 16$} & 600 & 72.50 & 4.19 & 0.91 & 29.12 & 21.51 \\
\hline & 800 & 55.00 & 5.68 & 1.24 & 35.72 & 21.61 \\
\hline & 1000 & 82.50 & 5.90 & 1.30 & 36.40 & 22.01 \\
\hline \multirow[t]{4}{*}{$29 / 19$} & 400 & 45.00 & 7.13 & 1.35 & 32.27 & 18.86 \\
\hline & 600 & 57.50 & 9.02 & 1.38 & 37.50 & 15.32 \\
\hline & 800 & 87.50 & 9.50 & 1.39 & 39.22 & 14.90 \\
\hline & 1000 & 47.50 & 8.97 & 1.30 & 38.02 & 14.51 \\
\hline \multirow[t]{4}{*}{$32 / 22$} & 400 & 40.00 & 11.20 & 1.70 & 40.47 & 15.06 \\
\hline & 600 & 50.00 & 10.79 & 1.86 & 40.72 & 17.42 \\
\hline & 800 & 60.00 & 13.36 & 2.01 & 45.05 & 15.16 \\
\hline & 1000 & 55.00 & 11.33 & 1.79 & 41.80 & 15.69 \\
\hline Ortalama & $26 / 16$ & 76.25 & $5.15 c$ & $1.11 \mathrm{~b}$ & $32.98^{c}$ & $21.42 a$ \\
\hline \multirow[t]{2}{*}{ Sıcaklık $\left({ }^{\circ} \mathrm{C}\right)$} & 29/19 & 59.37 & $8.66 \mathrm{~b}$ & $1.35 b$ & $36.75 b$ & $15.90 b$ \\
\hline & $32 / 22$ & 51.25 & $11.65 a$ & $1.84 a$ & $42.01 a$ & $15.83 b$ \\
\hline \multirow{4}{*}{$\begin{array}{l}\text { Ortalama } \mathrm{CO}_{2} \\
\text { (ppm) }\end{array}$} & 400 & 60.00 & 7.71 & 1.34 & $34.48 b$ & 18.15 \\
\hline & 600 & 57.50 & 7.98 & 1.38 & $35.78 b$ & 18.08 \\
\hline & 800 & 67.50 & 9.52 & 1.54 & $40.00 a$ & 17.22 \\
\hline & 1000 & 61.67 & 8.74 & 1.46 & $38.74 a$ & 17.41 \\
\hline F Sıcaklık & & $17.48^{* *}$ & $50.39^{* *}$ & $14.95^{* *}$ & $15.42^{* *}$ & $49,67^{* *}$ \\
\hline $\mathrm{FCO}_{2}$ & & $1.01^{\mathrm{ns}}$ & $2.36^{\mathrm{ns}}$ & $0.65^{\mathrm{ns}}$ & $3.67^{*}$ & $0.80^{\mathrm{ns}}$ \\
\hline F Sıcaklık $\times \mathrm{CO}_{2}$ & & $9.39^{* *}$ & $0.65^{\mathrm{ns}}$ & $0.41^{\mathrm{ns}}$ & $0.69^{\mathrm{ns}}$ & $2.99^{\text {ns }}$ \\
\hline
\end{tabular}

Çizelge 1. Artırılmış sıcaklık ve $\mathrm{CO}_{2}{ }^{\prime}$ in reyhan bitkisinin gelişimine olan etkisi 


\section{Çimlenme çalışmaları}

Mor renkli reyhan bitkisinin arttırılmış sıcaklık ve karbondioksitte tepkisinin araştırıldığı denemede çimlenme sonuçları incelendiğinde; en yüksek çimlenme oranı $\left(G_{\max }\right) 26 / 16{ }^{\circ} \mathrm{C}$ sıcaklıkta $\% 95$, en düşük çimlenme oranı ise $\% 40$ ile $32 / 22{ }^{\circ} \mathrm{C}$ sıcaklıkta elde edilmiştir. Ortalama sıcaklık değerlerinde, düşük sıcaklıkta $\left(26 / 16{ }^{\circ} \mathrm{C}\right)$ çimlenme oranı en yüksek düzeyde iken (\%76.25), sıcaklık değerinin artması $\left(32 / 22{ }^{\circ} \mathrm{C}\right)$ mor reyhan bitkisinin çimlenme oranının düşmesine neden olmuştur (Çizelge 1). Ortalama CO2 değerlerinde ise en yüksek çimlenme oranı 800 ppm $\mathrm{CO} 2$ uygulamasından elde edilmiştir (Çizelge 1). Bitkinin artan karbondioksite tepkisinde ise çimlenme oranı en düşük $\left(32 / 22{ }^{\circ} \mathrm{C}\right)$ ve en yüksek $\left(26 / 16{ }^{\circ} \mathrm{C}\right)$ değerini 400 ppm karbondioksit uygulamasından almıştır. Üç farklı sıcaklıkta reyhan bitkisi karbondioksit miktarının artmasına karşı negatif bir etki göstermiştir. Çimlenme oranları karbondioksit miktarı artıkça genel olarak düşmüştür. Düşük sıcaklıkta $\left(26 / 16{ }^{\circ} \mathrm{C}\right)$ karbondioksit miktarlarının artması (600-800-1000 ppm) düşük $\mathrm{CO}_{2}$ oranına göre $(400 \mathrm{ppm})$ çimlenme oranında $\left(\mathrm{G}_{\max }\right)$ azalmalara sebep olurken, , yüksek sıcaklıkta $\left(32 / 22{ }^{\circ} \mathrm{C}\right)$ ise çimlenme oranı $400 \mathrm{ppm} \mathrm{CO}_{2}$ 'ye göre diğer $\mathrm{CO}_{2}$ oranlarında (600, 800 ve 1000 ppm) artmıştır. Sıcaklıkla birlikte ortamdaki karbondioksit miktarının artması reyhan bitkisinin çimlenme oranını düşürerek hayatta kalabilmesini ve hayatını devam ettirmesini riske atmaktadır. Bu durum 29/19 ${ }^{\circ} \mathrm{C}$ sıcaklıkta artan karbondioksitte (1000 ppm hariç) (600-800 ppm) yetişen mor reyhan bitkilerinde de gözlenmiştir. 29/19 ${ }^{\circ} \mathrm{C}$ sıcaklıkta sadece 800 ppm $\mathrm{CO}_{2}{ }^{\prime}$ de $\% 87.50$ oranında ikinci en yüksek çimlenme oranına ulaşılmıştır (Çizelge 1). Daha önceki çalışmalarda sıcaklığın tohum çimlenmesini etkileyen en önemli ve kritik faktörlerden biri olduğu (Baskin ve Baskin, 2001; Verma ve ark., 2010; Kumar ve ark., 2011) ve $\mathrm{CO}_{2}$ miktarındaki artışın bazı bitki türlerinin çimlenme veya çıkışını etkilediği (Ziska ve Bunce 1993) ayrıca reyhan bitkisinin optimum çimlenme sıcaklıklarının $25-40{ }^{\circ} \mathrm{C}$ arasında olduğu (Zhou ve Welbaum, 2012) bildirilmiştir. Ayrıca diğer bazı çalışmalarda da değişik bitkilerde yüksek sıcaklığın (Baskin ve Baskin, 1998; Govinthasamy, 1994; Hume 1994) ve yüksek $\mathrm{CO}_{2}$ oranının (Farnsworth ve Bazzaz, 1995; Qaderi ve Reid, 2008) çimlenme oranlarını düşürdüğü sonuçları ile çalışmamız benzerlik göstermektedir. Diğer taraftan, denemede kullanılan yerel çeşit olan mor reyhanın çimlenmesi için ise $20{ }^{\circ} \mathrm{C}$ ve üzeri sıcaklığa ihtiyaç duyulmaktadır (Anonim, 2019). Bu durum çalışmada en uygun çimlenme sıcaklığının $26{ }^{\circ} \mathrm{C}$ ve 400 ppm $\mathrm{CO}_{2}$ 'de yetiştirilmesinde elde edilen sonuçlarla uyum göstermektedir. Diğer taraftan
IPCC (2007)'nin verilerine göre Dünyadaki ortalama sıcaklık ve $\mathrm{CO}_{2}$ değerlerinin $26{ }^{\circ} \mathrm{C}$ ve $400 \mathrm{ppm}$ olduğu göz önüne alındığında ileriki yıllarda küresel ısınma sonucu mor reyhan bitkilerinin çimlenmesinin önemli ölçüde olumsuz etkilenebileceği sonucu ortaya çıkmaktadır.

\section{Bitkisel gelişmeler Bitki boyu}

Bitki boyunda hem sıcaklık $(p<0.01)$ hem de karbondioksit konsantrasyonları $(p<0.05)$ etkili olmuştur. Yüksek sıcaklık bitki boyunu artırırken

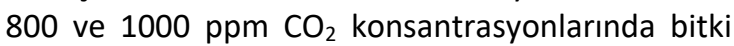
boyları diğer konsantrasyonlardan (400 ve 600 ppm) daha yüksek bulunmuştur (Çizelge 1). En düşük bitki boyu $26 / 16{ }^{\circ} \mathrm{C}$ sıcaklıktan alınırken en yüksek bitki boyu $32 / 22{ }^{\circ} \mathrm{C}$ sıcaklıkta alınmıştır. Sıcaklığın artışı bitki boyunun artmasına neden olmuştur. Yüksek sıcaklıkla birlikte karbondioksit miktarının artması da bitki boyunun artmasına neden olmuştur. 800 ve 1000 ppm $\quad \mathrm{CO}_{2}$ konsantrasyonlarında bitki boyları diğer konsantrasyonlardan (400 ve 600 ppm) daha yüksek bulunmuştur (Çizelge 1). Benzer şekilde Lavanya ve ark. (2017) da arttırılmış $\mathrm{CO}_{2}$ ve sıcaklığın dut bitkisinde bitki boyuna olumlu etki yaptığını ve diğer taraftan Tursun ve ark. (2017)'da stevia ve melisa bitkilerinde arttırılmış sıcaklık ve $\mathrm{CO}_{2}{ }^{\prime}$ in bitki boyu, yaş ve kuru ağırlıkları olumlu yönde etkilediği sonuçlarını elde etmişlerdir. Yaptığımız çalışmada da benzer şekilde sıcaklıkla beraber $\mathrm{CO}_{2}$ miktarının artışı, bitkilerin fotosentez etkililiğini artırarak daha fazla boy artışına sebep olduğu sonucunu ortaya çıkarmaktadır.

\section{Taze herba verimi}

En yüksek taze herba verimi $32 / 22{ }^{\circ} \mathrm{C}$, en düşük taze herba verimi $26 / 16{ }^{\circ} \mathrm{C}$ sıcaklıktan elde edilmiştir. Sıcaklık artışıyla birlikte reyhan bitkisinin taze herba veriminde önemli bir artış elde edilirken, $\mathrm{CO}_{2}$ uygulamalarının reyhan bitkisinin taze herba verimi üzerine etkisi olmamıştır (Çizelge 1). Ayrıca bitkiler düşük sıcaklık rejimlerinde yetiştirildiklerinde düşük $\mathrm{CO}_{2}$ asimilasyonu ve düşük büyüme oranlarına sahip olmaktadırlar (Markhart ve ark., 1980; Raper ve Kramer, 1980). Bu duruma benzer şekilde yaptığımız çalışmada reyhan bitkisinin düşük sıcaklıkta daha az büyüme göstermesi ve bunun sonucunda da daha düşük taze herba verimi elde edilmesi sonucunu ortaya çıkarmaktadır. Diğer taraftan, Wheeler ve ark., (1994) artan $\mathrm{CO}_{2}$ konsantrasyonunun ve sıcaklığın havuç verimini artırmasına rağmen sıcaklık ve $\mathrm{CO}_{2}$ arasında bir interaksiyonun olmadığını belirlemişlerdir. Çalışmamızda da sıcaklık ve $\mathrm{CO}_{2}$ arasındaki interaksiyon önemsiz bulunmasına rağmen yüksek sıcaklık ve karbondioksitte taze herba verimi daha fazla elde edilmiştir (Çizelge 1 ). Diğer taraftan çalışmamızda kullandığımız reyhan 
bitkisi $C_{3}$ sistemi ile fotosentez yapan bir bitkidir (Duke, 1991). Aranjuelo ve ark. (2013), yüksek $\mathrm{CO}_{2}$ oranlarının $\mathrm{C}_{3}$ bitkilerinde fotosentezin artmasına yol açarak verimde artışlara neden olduğunu bildirmiştir. Long ve ark., (2006), $\mathrm{CO}_{2}$ artışının $\mathrm{C}_{3}$ bitkilerinde yaprak yüzeyindeki stoma yoluyla dış hava ile temas halinde olan fotosentetik işlemler için RuBisCO'yu kullandığını, ortamdaki $\mathrm{CO}_{2}$ seviyesinin artması ile rekabet halindeki oksijenasyon reaksiyonunun oluşmasının engellendiği ve sonuçta da fotosentez oranını artığını ve artan fotosentez oranının bitkilerin yapılarına daha fazla karbon ekleyerek biyokütlelerini artırmalarına olanak sağladığını bildirmektedirler. Sharma ve ark., (2020) da yüksek sıcaklık ve $\mathrm{CO}_{2}$ oranı Hypericum perforatum'da toprak üstü biyokütlesini arttırdığını bildirmişlerdir. Kimball (1983)'da $\mathrm{CO}_{2}^{\prime}$ 'nin iki katına çıkmasının fesleğende bitki büyümesini yaklaşık \%33 arttırdığını ortaya koymaktadır. Bütün bu araştırmalar ışığında çalışmamızda kullandığımız mor reyhan bitkisinde taze herba veriminin sıcaklık ve $\mathrm{CO}_{2}$ artışı ile olumlu yönde etkilendiği sonucu belirlenmiş ve yapılan çalışmalarla benzerlik göstermiştir.

\section{Kuru herba verimi}

Reyhan bitkisinin kuru herba verimi taze herba verimine benzer şekilde elde edilmiştir. İstatistiki olarak sıcaklıklar önemli bulunurken, $\mathrm{CO}_{2}$ ve sıcaklık $\times \mathrm{CO}_{2}$ interaksiyonu önemli bulunmamıştır. En yüksek kuru madde verimi 32/22 ${ }^{\circ} \mathrm{C}$ sıcaklıkta 800 ve 1000 ppm karbondioksiten elde edilmiştir (Çizelge 1). Koch ve ark. (1983) turunçgil fidelerinde yaptıkları çalışmalarda 360 ve 660 ppm CO${ }_{2}^{\prime}$ de 14 hafta boyunca yetiştirdikleri çalışma sonunda zenginleştirilmiş $\mathrm{CO}_{2}$ 'de bitkilerin yapraklarının ve gövdelerinin kuru ağırlıklarında artış olduğunu belirlemişlerdir. Ayrıca soya fasulyesi üzerine yapılan diğer bir çalışmada ise; bitkilerin yaprak ve toplam kuru madde üretimi, artırılmış $\mathrm{CO}_{2}(800$ ppm)'de daha fazla olduğunu bildirmişlerdir (Madhu ve Hatfield, 2015). Çalışmamızda da $\mathrm{CO}_{2}$ seviyesinin artması reyhan bitkisinde kuru madde miktarını arttırmış ve bu durum yapılan çalışmalarla benzerlik göstermiştir.

\section{Element analizleri}

Reyhan bitkisinin element analizi incelendiğinde; N sıcaklık artışı ile artarken, karbonioksit konsantrasyonlarının artışında ise dalgalanmalar göstermiştir. En yüksek $\mathrm{N}$ içeriği $32 / 22{ }^{\circ} \mathrm{C}$ sıcaklıkta 800 ppm $\mathrm{CO}_{2}$ 'den elde edilmiştir. $\mathrm{K}$ ve $\mathrm{Ca}^{\prime}$ da N'ye benzer değişim göstermiştir. Bu elementlerin hepsinde en yüksek değerler $32 / 22{ }^{\circ} \mathrm{C}$ sıcaklıktan elde edilmiştir. $\mathrm{P}$ ve $\mathrm{Zn}$ ise en yüksek $29 / 19{ }^{\circ} \mathrm{C}^{\prime}$ de saptanmıştır (Çizelge 2).

Çizelge 2. Artırılmış sıcaklık ve $\mathrm{CO}_{2}{ }^{\prime}$ in reyhan bitkisinin bitki besin elementlerine olan etkisi

\begin{tabular}{|c|c|c|c|c|c|c|c|c|c|c|}
\hline $\begin{array}{c}\text { Sıcaklık } \\
\left({ }^{\circ} \mathrm{C}\right)\end{array}$ & $\begin{array}{c}\mathrm{CO}_{2} \\
(\mathrm{ppm})\end{array}$ & $\begin{array}{l}\mathrm{N} \\
\%\end{array}$ & $\begin{array}{l}\mathrm{P} \\
\%\end{array}$ & $\begin{array}{l}K \\
\%\end{array}$ & $\begin{array}{l}\mathrm{Ca} \\
\%\end{array}$ & $\begin{array}{c}\mathrm{Mg} \\
\%\end{array}$ & $\begin{array}{c}\mathrm{Cu} \\
\mathrm{mg} \mathrm{kg}^{-1}\end{array}$ & $\begin{array}{c}\mathrm{Mn} \\
\mathrm{mg} \mathrm{kg}^{-1}\end{array}$ & $\begin{array}{c}\mathrm{Fe} \\
\mathrm{mg} \mathrm{kg}^{-1}\end{array}$ & $\begin{array}{c}\mathrm{Zn} \\
\mathrm{mg} \mathrm{kg}^{-1}\end{array}$ \\
\hline \multirow{4}{*}{$26 / 16$} & 400 & 0.95 & 0.15 & 1.20 & 1.08 & 0.70 & 3.05 & 77.35 & 105.5 & 22.48 \\
\hline & 600 & 0.69 & 0.16 & 0.55 & 1.29 & 0.80 & 9.20 & 86.10 & 123.4 & 54.21 \\
\hline & 800 & 0.64 & 0.16 & 0.50 & 1.26 & 0.56 & 6.90 & 75.70 & 115.00 & 48.35 \\
\hline & 1000 & 0.58 & 0.17 & 0.78 & 1.69 & 0.90 & 5.70 & 122.30 & 96.70 & 69.36 \\
\hline \multirow{4}{*}{ 29/19 } & 400 & 1.59 & 0.28 & 2.47 & 1.90 & 0.53 & 9.00 & 72.10 & 136.70 & 71.09 \\
\hline & 600 & 1.40 & 0.25 & 2.17 & 1.88 & 0.51 & 8.70 & 89.20 & 150.90 & 67.35 \\
\hline & 800 & 1.47 & 0.16 & 1.95 & 1.35 & 0.45 & 4.30 & 54.15 & 41.50 & 38.88 \\
\hline & 1000 & 1.23 & 0.16 & 1.25 & 1.52 & 0.52 & 2.95 & 53.10 & 103.85 & 33.19 \\
\hline \multirow{4}{*}{$32 / 22$} & 400 & 2.30 & 0.25 & 4.98 & 2.22 & 0.59 & 6.25 & 61.70 & 64.95 & 59.21 \\
\hline & 600 & 1.94 & 0.23 & 3.82 & 2.09 & 0.59 & 4.10 & 65.70 & 85.75 & 60.54 \\
\hline & 800 & 2.54 & 0.19 & 4.11 & 2.09 & 0.59 & 3.95 & 52.05 & 51.10 & 33.36 \\
\hline & 1000 & 1.34 & 0.20 & 3.38 & 1.77 & 0.62 & 4.10 & 55.90 & 52.95 & 44.17 \\
\hline \multirow[t]{3}{*}{ Sıcaklık $\left({ }^{\circ} \mathrm{C}\right)$} & $26 / 16$ & 0.71 & 0.16 & 0.76 & 1.33 & 0.74 & 6.21 & 90.36 & 86.41 & 48.60 \\
\hline & 29/19 & 1.42 & 0.21 & 1.96 & 1.66 & 0.50 & 6.24 & 67.14 & 108.24 & 52.63 \\
\hline & $32 / 22$ & 2.03 & 0.22 & 4.07 & 2.04 & 0.60 & 4.60 & 58.84 & 63.69 & 49.32 \\
\hline \multicolumn{11}{|l|}{ Ortalama } \\
\hline $\mathrm{CO}_{2}$ & 400 & 1.61 & 0.23 & 2.88 & 1.74 & 0.61 & 6.10 & 70.38 & 70.73 & 50.93 \\
\hline \multirow[t]{3}{*}{ (ppm) } & 600 & 1.34 & 0.21 & 2.18 & 1.75 & 0.64 & 7.33 & 80.33 & 120.02 & 60.70 \\
\hline & 800 & 1.55 & 0.17 & 2.19 & 1.56 & 0.53 & 5.05 & 60.63 & 69.20 & 40.20 \\
\hline & 1000 & 1.05 & 0.18 & 1.80 & 1.66 & 0.68 & 4.25 & 77.10 & 84.50 & 48.91 \\
\hline
\end{tabular}


$\mathrm{Mg}$ sıcaklık ve $\mathrm{CO}_{2}$ konsantrasyonlarında düzenli bir değişim olmamış, düşük sıcaklıkta $\mathrm{CO}_{2}$ uygulamaları arasındaki değişim fazla olurken; diğer iki sıcaklıkta değişen $\mathrm{CO}_{2}$ konsatrasyonlarında $\mathrm{Mg}$ konsantrasyonu dar bir sınır içerisinde değişim göstermiştir. $\mathrm{Cu}$ konsantrasyonları $26 / 16{ }^{\circ} \mathrm{C}$ ve $29 / 19{ }^{\circ} \mathrm{C}$ sıcaklık ortamlarındaki değerler, $32 / 22{ }^{\circ} \mathrm{C}$ sıcaklıktakinden yüksek bulunmuştur. $\mathrm{CO}_{2}$ konsantrasyonların ortalamasında 600 ppm'de en yüksek değer elde edilmiştir. $\mathrm{Mn}$ konsantrasyonunda sıcaklık artışıyla azalma görülmüş, en yüksek değer $26 / 16{ }^{\circ} \mathrm{C}$ de 1000 ppm $\mathrm{CO}_{2}$ uygulamasından elde edilmiştir. $\mathrm{Fe}$ konsantrasyonu tüm sıcaklıklarda 600 ppm CO 2 uygulamasında en yüksek değer alınmış bunun sonucu olarak ortalama $\mathrm{CO}_{2}$ değerlerde de 600 ppm diğer sıcaklık ortalamalarından yüksek olmuştur. Sıcaklık ortalamasında 29/19 ${ }^{\circ} \mathrm{C}$ Fe miktarları diğer sıcaklık ortalamalarından yüksek olmuştur (Çizelge 2).

$\mathrm{CO}_{2}$ artışı bitki türlerine bağı olarak $\mathrm{N}$ içeriğinde artışlar ve azalışlara sahip olabilmektedir (Dong ve ark. 2018b). Örneğin, Lavanya ve ark. (2017) dut bitkisinde Dong ve ark. (2018a) hıyarda, Jin ve ark. (2009) kuşkonmazda arttırılmış $\mathrm{CO}_{2}^{\prime}$ nin yapraklarda N içeriğinde azalmalara sebep olduğunu belirlerken; Wei ve ark. (2018) domateste, Jin ve ark. (2009) ise kerevizde artışların olduğunu bildirmişlerdir. Yaptığımı çalışmada reyhan bitkisi için $\mathrm{N}$ içeriğinde $\mathrm{CO}_{2}$ artışının olumsuz etkide bulunduğu belirlenmiştir. Dong ve ark. (2018b) artırılmış $\mathrm{CO}_{2}^{\prime}$ in sebzelerde $\mathrm{Mg}, \mathrm{Fe}$ ve $\mathrm{Zn}$ elementlerinde düşüşler meydana getirdiğini; $\mathrm{Ca}$ elementinde artışların olduğunu; buna karşılık $\mathrm{P}, \mathrm{K}, \mathrm{Cu}$ ve $\mathrm{Mn}$ de ise bir değişiklik olmadığını belirtmiştir. Çalışmamızda ise bu elementlerden $\mathrm{CO}_{2}$ artışı $\mathrm{P}, \mathrm{K}, \mathrm{Cu}, \mathrm{Ca}$ ve $\mathrm{Fe}^{\prime}$ de azalışlara neden olurken; diğer elementlerde düzenli bir değişim gözlenmemiştir. Bu durum uygulamalara göre değişimlerin bitki türlerine göre farklılık gösterebileceğini işaret etmektedir. Diğer taraftan stres koşullarında bir veya daha fazla besin elementi konsantrasyonu büyüme performansına bağlı olarak seyrelme etkisi veya akümülasyon etkisi ortaya çıkabilmektedir. Bu nedenle bitkinin element bileşiminden ziyade Çizelge 3 'te verilen topraktan kaldırılan miktarlar hem bitkinin elementel bileşimini hem de büyüme performansını birlikte göz önüne alındığından daha sağlıklı değerlendirme yapma imkanı sağlayabilmektedir (Uygur ve Yetişir, 2009). Topraktan kaldırılan N, K, P ve Ca gibi makro elementler benzer davranış göstermiş, sıcaklıktaki artışla topraktan kaldırılan besin elementi miktarında artışlar gözlenmiştir.

Çizelge 3. Artırılmış sıcaklık ve karbondioksitin Reyhan bitkisinin topraktan kaldırdığı besin elemneti miktarlarına olan etkisi

\begin{tabular}{|c|c|c|c|c|c|c|c|c|c|c|}
\hline $\begin{array}{l}\text { Sicaklık } \\
\left({ }^{\circ} \mathrm{C}\right)\end{array}$ & $\begin{array}{l}\mathrm{CO} 2 \\
(\mathrm{ppm})\end{array}$ & $\begin{array}{l}\mathbf{N} \\
\text { mg/bitki }\end{array}$ & $\begin{array}{l}\mathbf{P} \\
\mathrm{mg} / \text { bitki }\end{array}$ & $\begin{array}{l}\mathbf{K} \\
\mathrm{mg} / \text { bitki }\end{array}$ & $\begin{array}{l}\text { Ca } \\
\text { mg/bitki }\end{array}$ & $\begin{array}{l}\text { Mg } \\
\text { mg/bitki }\end{array}$ & $\begin{array}{l}\mathrm{Cu} \\
\mathrm{mg} / \text { bitki }\end{array}$ & $\begin{array}{l}\text { Mn } \\
\text { mg/bitki }\end{array}$ & $\begin{array}{l}\text { Fe } \\
\mathrm{mg} / \text { bitki }\end{array}$ & $\begin{array}{l}\text { Zn } \\
\text { mg/bitki }\end{array}$ \\
\hline \multirow{4}{*}{$26 / 16$} & 400 & 9.29 & 1.48 & 11.81 & 10.66 & 6.84 & 3.00 & 76.04 & 103.71 & 22.10 \\
\hline & 600 & 6.27 & 1.49 & 5.03 & 11.74 & 7.30 & 8.35 & 78.18 & 112.05 & 49.22 \\
\hline & 800 & 7.97 & 2.00 & 6.25 & 15.54 & 6.98 & 8.54 & 93.72 & 142.37 & 59.86 \\
\hline & 1000 & 7.54 & 2.25 & 10.19 & 22.03 & 11.77 & 7.43 & 159.36 & 126.00 & 90.38 \\
\hline \multirow{4}{*}{ 29/19 } & 400 & 21.40 & 3.76 & 33.24 & 25.56 & 7.14 & 12.11 & 96.97 & 183.86 & 95.62 \\
\hline & 600 & 19.40 & 3.41 & 30.13 & 26.07 & 7.14 & 12.06 & 123.63 & 209.15 & 93.35 \\
\hline & 800 & 20.54 & 2.18 & 27.10 & 18.74 & 6.21 & 5.99 & 75.43 & 57.81 & 54.15 \\
\hline & 1000 & 16.00 & 2.13 & 16.28 & 19.88 & 6.80 & 3.85 & 69.24 & 135.42 & 43.28 \\
\hline \multirow[t]{4}{*}{$32 / 22$} & 400 & 21.40 & 3.76 & 33.24 & 25.56 & 7.14 & 12.11 & 96.97 & 183.86 & 95.62 \\
\hline & 600 & 19.40 & 3.41 & 30.13 & 26.07 & 7.14 & 12.06 & 123.63 & 209.15 & 93.35 \\
\hline & 800 & 20.54 & 2.18 & 27.10 & 18.74 & 6.21 & 5.99 & 75.43 & 57.81 & 54.15 \\
\hline & 1000 & 16.00 & 2.13 & 16.28 & 19.88 & 6.80 & 3.85 & 69.24 & 135.42 & 43.28 \\
\hline \multirow{3}{*}{$\begin{array}{l}\text { Sicaklık } \\
\left({ }^{\circ} \mathrm{C}\right)\end{array}$} & $26 / 16$ & 7.77 & 1.81 & 8.32 & 14.99 & 8.22 & 6.83 & 101.83 & 121.03 & 55.39 \\
\hline & 29/19 & 19.34 & 2.87 & 26.69 & 22.56 & 6.82 & 8.50 & 91.32 & 146.56 & 71.60 \\
\hline & $32 / 22$ & 37.58 & 4.00 & 74.72 & 37.62 & 10.98 & 8.39 & 108.00 & 116.91 & 89.90 \\
\hline \multirow{4}{*}{$\begin{array}{l}\text { Ortalama } \\
\mathrm{CO}_{2} \\
(\mathrm{ppm})\end{array}$} & 400 & 23.27 & 3.17 & 43.23 & 24.68 & 8.02 & 8.58 & 92.63 & 132.66 & 72.79 \\
\hline & 600 & 20.58 & 3.06 & 35.41 & 25.56 & 8.45 & 9.35 & 108.00 & 160.23 & 85.06 \\
\hline & 800 & 26.51 & 2.64 & 38.60 & 25.40 & 8.34 & 7.48 & 91.19 & 100.90 & 60.31 \\
\hline & 1000 & 15.89 & 2.68 & 29.07 & 24.59 & 9.90 & 6.22 & 109.70 & 118.87 & 71.03 \\
\hline
\end{tabular}


Mikro besin elmenlerinden Zn sıcaklık artışına bağlı olarak artış gösterirken; diğer elementler belirgin bir eğilime sahip değildir. Sıcaklık artışıyla beraber bitkilerin bünyesinden geçen su miktarında artış olmaktadır (Shani ve Dudley, 2001). Artan su miktarı, besin elementlerinin yeterli miktarda sağlandığı büyüme ortamlarında, özellikle pasif taşınma süreciyle bitkiler tarafından alınan elementlerin daha fazla miktarda alınmasına neden olmaktadır (Uygur ve Yetişir, 2009). Diğer taraftan artan sıcaklığın bir fonksiyonu olarak elementlerin toprak çözeltisindeki konsantrasyonunda artışlar söz konusudur. Bu iki temel olgunun daha fazla besin elementi alınmasında rol oynadığı değerlendirilmiştir. Ayrıca, artan sıcaklık ile bitkilerin kök gelişiminde de değişikliklere neden olmaktadır (Marschner, 1995) ki bu da nihai noktada bitkilerin gelişimi ve topraktan kaldırdığı besin elementi miktarında belirleyici rol oynamaktadır.

\section{Sonuç ve Öneriler}

Sanayileşmenin sonucunda artan $\mathrm{CO}_{2}$ miktarı ve küresel ısınma neticesinde bitkilerin büyüme-gelişme, besin elementi alımları ve diğer birçok fizyolojik sürecin bitkileri etkileyeceği belirtilebilir. Çalışmanın yapıldığı reyhan bitkisinde sıcaklık artışları çimlenme oranlarında düşüşler meydana getirirken, sıcaklık artışları çimlenen bitkilerin büyümesini teşvik etmiştir. Diğer taraftan $\mathrm{CO}_{2}$ konsantrasyonundaki artış belirgin bir etkiye neden olmamıştır. Sıcaklık reyhanın topraktan kaldırdığı besin elementi miktarına özellikle de makro elementler üzerine etkisi son derece belirgin olmuştur. Dolayısıyla değişik koşullar altında bitki besin elementlerinin topraktaki yarayışlılığı dikkatle kontrol altında tutulması gerekmektedir. Bütün bu sonuçlar ışığında sıcaklık artışları reyhan bitkisinde belirgin bir etkiye sahip olurken, karbondioksit artışlarında ise dalgalanmalar görülmüştür. Tıbbı ve aromatik bitkiler içerisinde önemli bir yere sahip olan reyhan bitkisinde, ileriki dönmelerde küresel iklim değişikleri içerisinde yer alan sıcaklık artışlarının olumsuz yönde etkilerinin ortaya çıkabileceği açıktır.

Çıkar Çatışması Beyanı: Makale yazarları aralarında herhangi bir çıkar çatışması olmadığını beyan ederler.

Araştırmacıların Katkı Oranı Beyan Özeti: Yazarlar makaleye eşit oranda katkı sağlamış olduklarını beyan ederler.

\section{Kaynaklar}

Anonim. 2019. Arapgir mor reyhanın başarı öyküsü. http://www.turktarim.gov.tr/.

Aranjuelo, I., Sanz-Sáez, Á., Jauregui, I., Irigoyen, J.J., Araus, J.L. ve Sánchez-D’iaz, M. 2013. Harvest index, a parameter conditioning responsiveness of wheat plants to elevated $\mathrm{CO}_{2}$. Journal of Experimental Botany, 64 (7):1879-1892.

Baker, J.T., Allen, L.H. Jr., Boote, K.J., Jones, P. ve Jones, J.W. 1989. Response of soybean to air temperature and carbon dioxide concentration. Crop Science, 29: 98-105.

Baskin C.C. ve Baskin, J.M. 1998. Seeds: ecology, biogeography, and evolution of dormancy and germination. Academic Press, San Diego, CA. 680 pp.

Baskin, C.C. ve Baskin J.M. 2001. Seeds: Ecology, biogeography, and evolution of dormancy and germination. Waltham, MA: Academic Press.

Bassiouny, S.S., Hassanien F.R., Ali, F.R. ve Kayati, S.M.E. 1990. Efficiency of antioxidants from natural sources in bakery products. Food Chemistry, 37: 297-305.

Böttcher, F. 1993. Science and fiction of the greenhouse effect and carbondioxide, change. Research and Policy Newsletter on Global Change, 13: 3-5.

Cox, P.M., Betts, R.A, Jones, C.D., Spall, S.A. ve Totterdell, I.J. 2000. Acceleration of global warming due to carbon-cycle feedbacks in a coupled model. Nature, 408: 184-187.

Davidson, E.A. ve Janssens, I.A. 2006. Temperature Sensitivity of Soil Carbon Decomposition and Feedbacks to Climate Change. digital object identifier

(doi):10.1038/nature04514Vol

$44 \mid$ March;9

Deshpande, R.S. ve Tipnis, H.P. 1997. Insecticidal activity of Ocimum basilicum L.. Pesticides, 11: 1-12.

Dong, J., Li, X., Gruda, N., ve Duan, Z. 2018 a. Interactive effects of elevated carbon dioxide and nitrogen availability on fruit quality of cucumber (Cucumis sativus L.). Journal of Integrative Agriculture, 17(11): 2438-2446.

Dong, J., Gruda, N., Lam, S.K., Li, X. ve Duan, X. 2018b. Effects of elevated $\mathrm{CO}_{2}$ on nutritional quality of vegetables: A Review. Frontiers in Plant Science, 9: 924.

Duke, J.A., 1991. Handbook of medicinal herbs. CRC Press, Inc., Boca Raton, FL.

Erbs, M., Franzaring, J., Högy, P. ve Fangmeier, A. 2009. Free-air $\mathrm{CO}_{2}$ enrichment in a wheat- 
weed assembly-effect on water relations. Basic and Apllied Ecology, 10: 358-367.

Etheridge, D.M., Steele, L.P., Langenfelds, R.L., Francey, R.J., Barnola J.M., ve Morgan, V.I. 1996. Natural and anthropogenic changes in atmospheric $\mathrm{CO}_{2}$ over the last 1000 years from air in Antarctic ice and firn. Journal of Geophysical Research,101: 4115-4128.

Farnsworth, E.J. ve Bazzaz, F.A. 1995. Inter- and intra-generic differences in growth, reproduction, and fitness of nine herbaceous annual species grown in elevated $\mathrm{CO}_{2}$ environments. Oecologia, 104: 454-466.

Franz, E.H. 1990. In Soils on a Warmer Earth (eds.: Scharpenseel, H. W., Schomaker, M. ve Ayoub, A.) ss.109-120, Elsevier, Amsterdam.

Govinthasamy, T. 1994. Effects of smut, mechanical damage, and emergence time on seed characters of fall panicum (Panicum dichotomiflorum Michx.). MS thesis. University of Western Ontario, London.

Hansen, J., Sato, M., Ruedy, R., Lacis, A. ve Oinas, V., 2000. Global warming in the twenty first century: An alternative scenario. Proceedings of the National Academy of Sciences of the United States of America, 97 (18): 9875-9880.

Hume, L, 1994. Maternal environment effects on plant growth and germination of two strains of Thlaspi arvense L. International Journalof Plant Sciences, 155: 180-186

IPCC, 2007. "Climate Change 2007 Synthesis Report: Summary for Policymakers", http://www.ipcc.ch/pdf/assessmentreport/ar4/syr/ar4_syr__ spm.pdf, 12.05.2009.

IPCC, 2014. The Fifth Assessment Report (AR5), The Intergovernmental Panel on Climate Change, Geneva, Switzerland, (http://www.ipcc.ch.).

Jenkinson, D.S., Adams, D.E., Wild, A. 1991. Model Estimates of $\mathrm{CO}_{2}$ Emissions from Soil in Response to Global Warming. Nature, 351(1): 304-306.

Jin, C., Du, S., Wang, Y., Condon, J., Lin, X., ve Zhang, Y. 2009. Carbon dioxide enrichment by composting in greenhouses and its effect on vegetable production. Journal of Plant Nutrition and Soil Science, 172: 418-424.

Kacar, B. ve İnal, A. 2008. Bitki Analizleri. Nobel Yayınları, Yayın No: 1241, Fen Bilimleri, 892. Nobel Yayın Dağıtım Ltd. Şti. Ankara, $892 \mathrm{~s}$.

Kacar, B. ve İnal, A. 2010. Bitki analizleri. Nobel Akademik Yayınları.
Kadıoğlu, M. 2008. Günümüzden 2100 Yılına Küresel İklim Değişikliği. TMMOB İklim Değişikliği Sempozyumu 13-14 Mart 2008 Ankara.

Keeling, C.D. ve Whorf, T.P. 2000. Atmospheric $\mathrm{CO}_{2}$ records from sites in the SIO air sampling network. In: Trends: A compendium of data on global change. Carbon Dioxide Information Analysis Center, Oak Ridge National Laboratory, Oak Ridge, Tenn., USA.

Kimball, J.S. 1983. Carbon dioxide and agricultural yield: Assemblage and anaysis of 430 prior observations. Argonomy Journal, 75: 779-788.

Koch, K.E., White, D.W., Jones, P.H. ve Allen, Jr.L.H. 1983. $\mathrm{CO}_{2}$ enrichment of carrizo citrange and swingle citrumelo rootstocks. Proceedings of the Florida State Horticultural Society, 96: 37-40.

Kumar, B., Verma, S.K. ve Singh, H.P. 2011. Effect of temperature on seed germination parameters in Kalmegh (Andrographis paniculata Wall. ex Nees.). Industrial Crops Products, 34 (1): 1241-1244.

Lavanya, C., Ashoka, J., Sreenivasa, A.G., Sushila, N.ve Beladhadi, B.V., 2017. Effect of elevated carbon dioxide and temperature on growth, yield and quality parameters of mulberry. Entomology, Ornithology \& Herpetology: Current Research, 6:3.

Long, S.P., Ainsworth, E.A., Leakey, A.D.B., Nösberger, J. ve Ort, D.R. 2006. Food for Thought: Lower-than-expected crop yield stimulations with rising $\mathrm{CO}_{2}$ concentrations. Science, 312: 1918-1921.

Madhu M. ve Hatfield J.L., 2015. Elevated carbon dioxide and soil moisture on early growth response of soybean. Agricultural Sciences, 6: 263-27.

Mall, R.K., Gupta, A., Singh, R., Singh, R.S. ve Rathore, L.S. 2006. Water resources and climate change: An Indian perspective. Current Science, 90:1610-1626.

Markhart, A.H., Peet, M.M., Sionit, N. ve Kramer, P.J. 1980. Low temperature acclimation of root fatty acid composition, leaf water potential, gas exchange and growth of soybean seedlings. Plant Cell \& Environment, 3(6):435-441.

Marschner, H., 1995. Mineral Nutrition of Higher Plants. Academic Press. San Diego. p. 889.

Mendelsohn, R. ve Rosenberg, N. 1994. Measuring the impact of global warming on agriculture. American Economic Review, 84: 753-771. 
Newman, Y.C., Sollenberger, L.E., Boote, K.j., Allen L.H. ve Littell, RC., 2001. Carbon dioxide and temperature effects on forage dry matter production. Crop Science, 41(2): 399-406.

Patel H.R., Patel, V.J. ve Pandey, V. 2008. Impact assessment of climate change on maize cultivars in middle Gujarat agro-climatic region using CERES maize model. Journal of Agrometeorology, 10 (2): 292-205.

Patel, D. ve Franklin, K.A. 2009. Temperatureregulation of plant architecture. Plant Signaling and Behavior Journal, 4: 577-579.

Qaderi, M.M. ve Reid, D.M. 2008. Combined Effects of Temperature and Carbon Dioxide on Plant Growth and Subsequent Seed Germinability of Silene noctiflora. International Journal of Plant Sciences, 169 (9): 1200-1209.

Raper, C.D., Jr. ve Kramer, P.J. 1980. Crop reactions to water and temperature stresses in humid, temperate climates. Westview Press, Boulder, Colorado. 373 pp.

Shani, U. ve Dudley, L.M. 2001. Field studies of crop response to water and salt stress. Soil Science Society of America Journal, 65: 1522-1528.

Sharma, S., Walia, S., Rathore, S., Kumar, P. Ve Kumar, R. 2020. Combined effect of elevated $\mathrm{CO}_{2}$ and temperature on growth, biomass and secondary metabolite of Hypericum perforatum L. in a western Himalayan region. Journal of Applied Researh on Medicinal and Aromatic Plants, 16: 1-10.

Simon, J.E., Quinn, J. ve Murray, R.G., 1990. Basil: A Source of Essential Oils. In: J. Janick and J.E. Simon (eds.), Advances in New Crops. Timber Press, Portland, 484-489.

Simon, J.E., Morales, M.R., Phippen, W.B., Vieira R.F. ve Haq, Z. 1999, Basil: A source of aroma compounds and a popular culinary and ornamental herb, p. 499-505.

Sionit, N., Strain, B.R. ve Flint, E.P. 1987a. Interaction of temperature and $\mathrm{CO}_{2}$ enrichment on soybean: Growth and dry matter partitioning. Canadian Journal Plant Science, 67: 59-67.

Sionit, N., Strain, B.R. ve Flint, E.P. $1987 b$. Interaction of temperature and $\mathrm{CO}_{2}$ enrichment on soybean: Photosynthesis and seed yield. Canadian Journal Plant Science, 67: 629-636.

Taylor, K.E. ve MacCracken, M.C., 1990. Projected effects of increasing concentrations of carbon Dioxide and Trace Gases on Climate. p.1-17.
Telci, İ., Bayram, E., Yılmaz, G., Avcı A.B. 2005. Türkiye'de kültürü yapılan yerel fesleğen (Ocimum spp.) genotiplerinin morfolojik, agronomik ve teknolojik özelliklerinin karakterizasyonu ve üstün bitkilerin seleksiyonu (Sonuç Raporu), TOGTAG-3102 Nolu Proje, TÜBITAK.

Telci, I., Bayram, E., Yılmaz, G. ve Avcı, B., 2006. Variability in essential oil composition of Turkish Basils (Ocimum basilicum L.). Biochemical Systematics and Ecology, 34: 489-497.

Telci, I., 2017. Morphological properties, chemical composition and using area of basil genotypes from Turkey. International Symposium on Medicinal, Aromatic and Dye Plants, 5-7 October Malatya, Turkey, s. 2935.

Tursun, A.Ö., Türk E. ve Üremiş, İ., 2017. Şekerotu (Stevia rebaudiana Bertoni) ve oğulotu (Melissa officinalis L.) bitkilerinin farklı sıcaklık ve $\mathrm{CO}_{2}$ konsantrasyonlarına tepkilerinin araştırılması. Journal of Agricultural Faculty of Mustafa Kemal University, 22 (2): 49-60.

Tursun, A.Ö. ve Telci, i., 2020. The effects of carbon dioxide and temperature on essential oil composition of purple basil (Ocimum basilicum L.). Journal of Essential Oil Bearing Plants Essential Oil Bearing Plants, 23 (2): 255-265.

Uygur, V. ve Yetişir, H. 2009. Effects of rootstocks on some growth parameters phosphorous and nitrogen uptake watermelon under salt stress. Journal of Plant Nutrition, 32: 629643.

Verma, S.K., Kumar, B., Ram, G., Singh, H.P. ve Lal, R.K. 2010. Varietal effect on germination parameter at controlled and uncontrolled temperature in Palmarosa (Cymbopogon martinii). Industrial Crops Products, 32: 696699.

Wei, Z., Du, T., Li, X., Fang, L., ve Liu, F. 2018. Interactive effects of elevated $\mathrm{CO}_{2}$ and $\mathrm{N}$ fertilization on yield and quality of tomato grown under reduced irrigation regime. Frontiers in Plant Science, 9: 328.

Wheeler, T.R., Morison, J.I.L., Ellis, R.H. ve Hadley, P. 1994. The effects of $\mathrm{CO}_{2}$, temperature and their interaction on the growth and yield of carrot (Daucus carota L.). Plant, Cell and Environment 17: 1275-1284.

Ziska, L.H. ve Bunce, A.J. 1993. The influence of elevated $\mathrm{CO}_{2}$ and temperature on seed germination and emergence from soil. Field Crops Research, 34 (2): 147-157. 
Ziska, L.H. 2000. The impact of elevated $\mathrm{CO}_{2}$ on yield loss from $C_{3}$ and $C_{4}$ weed in fieldgrown soybean. Global Change Biology, 6: 899-905.

Ziska, L.H. ve Goins, E.W. 2006. Elevated atmospheric carbon dioxide and weed populations in glyphosate treated soybean. Crop Science, 46: 1354-1359.

Zhou, E. ve Welbaum, G., 2012. Effects of temperature on sweet basil (Ocimum basilicum L.) germination. Visions for a Sustainable Planet ASA, CSSA and SSSA International Annual Meetings Oct. 21-24, 2012 Cincinati, Ohio.

Zhu, C.W., Zeng, Q., Ziska, L.H., Zhu, J.G., Xie, Z.B. ve Liu, G.L. 2008. Effect of nitrogen supply on carbon dioxide-induced changes in competition between rice and barnyardgrass (Echinochloa crus-galli). Weed Science, 56 (1): 66-71. 